Conclusions While $\mathrm{TH}$ has changed the predictive values of initial HIE grades, clinical staging at $<6 \mathrm{~h}$ correlates with outcome. The course of encephalopathy throughout $\mathrm{TH}$ is valuable in outcome prediction.

\section{PS-155 COMPARISON OF CLINICAL AND ELECTROPHYSIOLOGICAL SIGNS OF ENCEPHALOPATHY IN NEONATES WITH PERINATAL ASPHYXIA QUALIFYING FOR HYPOTHERMIA}

${ }^{1}$ A Vilan, ${ }^{2} \mathrm{LS}$ de Vries, ${ }^{3} \mathrm{P}$ Sá-Couto, ${ }^{2} \mathrm{IC}$ van Haastert, ${ }^{2} \mathrm{C}$ Koopman-Esseboom, ${ }^{2} \mathrm{MC}$ Toet, ${ }^{2}$ F Groenendaal. 'Neonatology, Centro Hospitalar São João, Porto, Portugal; ${ }^{2}$ Neonatology, Wilhelmina Children'S Hospital, Utrecht, Netherlands; ${ }^{3}$ Center for Research and Development in Mathematics and Applications, University of Aveiro, Aveiro, Portugal

\subsection{6/archdischild-2014-307384.451}

Background and aims Early prediction of neurodevelopmental outcome following hypoxic-ischaemic encephalopathy remains a challenge. The aim of this retrospective study was to evaluate the aEEG background patterns and Thompson score on admission in asphyxiated neonates receiving hypothermia regarding outcome and neonatal variables.

Methods After excluding congenital malformations and muscle paralysis, 89 neonates (January 2008 to June 2012) were included (GA: $39.7 \pm 1.8$ wks; BW: $3504 \pm 640$ g). On admission the Thompson score and aEEG were recorded. aEEG was scored as Continuous Normal Voltage (CNV), Discontinuous Normal Voltage (DNV), Burst-Suppression (BS), Continuous Low Voltage (CLV) or Flat Trace (FT). The combination of one or more of the following event (s): death, cerebral palsy, and Griffiths DQ less than 85 at 18 months were considered an adverse outcome. ANOVA, correlation, and binary logistic regression analyses were performed.

Results Thompson scores (in mean \pm sd) were associated with aEEG pattern (CNV: $8.3 \pm 1.7$; DNV: $8.9 \pm 1.9$; BS: $11.6 \pm$ 3.6; CLV: $12.0 \pm 2.1$; FT: $13.1 \pm 3.2$; p < 0.001). Also, both aEEG and Thompson score were statistically correlated with Apgar 1 and 5 min scores $(p<0.05)$. Using a logistic regression model, both Thompson score $(\mathrm{OR}=1.43 ; 95 \% \mathrm{CI}=$ $[1.15 ; 1.77])$ and aEEG pattern (BS: OR $=4.06 ; 95 \% \mathrm{CI}=$ $[0.74 ; 22.16] ;$ CLV: $\mathrm{OR}=11.10 ; 95 \% \mathrm{CI}=[1.38 ; 89.66] ; \mathrm{FT}$ : $\mathrm{OR}=13.35 ; 95 \% \mathrm{CI}=[1.87 ; 95.31]$; reference group: $\mathrm{CNV}$ + DNV) were significant predictors of an adverse outcome.

Conclusions Both Thompson scores and aEEG are associated with outcome in neonates receiving hypothermia for perinatal asphyxia and with $1 \mathrm{~min}$ Apgar scores. Further studies are needed to identify which method is preferable for selection of neonates for hypothermia.

\section{PS-156 ASSESSMENT OF MYOCARDIAL FUNCTION IN INFANTS RECEIVING THERAPEUTIC HYPOTHERMIA USING TISSUE DOPPLER IMAGING}

P Yajamanyam, RJS Negrine, SV Rasiah, AK Ewer. Neonatology, Birmingham Women's NHS Foundation Trust, Birmingham, UK

\subsection{6/archdischild-2014-307384.452}

Introduction Hypoxic ischaemic encephalopathy (HIE) may lead to cardiovascular dysfunction in newborn infants and conventional echocardiographic measures such as fractional shortening (FS) and left ventricular output (LVO) may not accurately detect cardiac dysfunction in these patients. ${ }^{1}$
Objective To evaluate cardiac dysfunction in HIE using tissue Doppler imaging (TDI). ${ }^{2}$

Methods 20 infants born at $\geq 36 \mathrm{w}$ gestation with HIE requiring therapeutic hypothermia (TH) were examined with serial conventional echocardiography and TDI on days 1, 2, 3 and after re-warming. Structural integrity of the heart was confirmed before obtaining measures of myocardial function (peak systolic (S'), early (E') and late diastolic (A') velocities, myocardial performance index (MPI) [using TDI], and FS and LVO). Measurements were also obtained from 10 healthy term infants as controls. Ethical approval and written parental consent were obtained.

Results Median gestation and birth weights of infants with HIE vs. controls was $39.6 \mathrm{w}$ vs. $40 \mathrm{w}$ and $3110 \mathrm{~g}$ vs. $3170 \mathrm{~g}$. On days 1, 2, 3 all myocardial velocities (MV), except left ventricular A' on day 3, were significantly lower $(<0.05)$ and MPI was significantly higher $(\mathrm{p} \leq 0.05)$ in the HIE group. After re-warming all MVs and MPIs were similar between the two groups. FS and LVO were similar between both groups on all days, except LVO on day 1 which was significantly lower in HIE infants $(\mathrm{p}<$ $0.05)$.

Conclusions TDI, compared to FS and LVO, may be better at detecting myocardial dysfunction in this group of babies and hence improve management of cardiac dysfunction.

\section{REFERENCES}

1. Armstrong K et al. Arch Dis Child 2012;97(4):372-5

2. Negrine RJS et al. Arch Dis Child Fetal Neonatal Ed 2012;97:F304-F306

\section{PS-157 MODERATE TO SEVERE NEONATAL ENCEPHALOPATHY IS PREDICTED BY RISING SERUM BUT NOT CSF BIOMARKERS}

'DU Sweetman, ${ }^{1} \mathrm{C}$ Onwuneme, ${ }^{2} \mathrm{~V}$ Donoghue, ${ }^{3} \mathrm{R}$ Segurado, ${ }^{4} \mathrm{RWG}$ Watson, ${ }^{1} \mathrm{EJ}$ Molloy. ${ }^{1}$ Neonatology, National Maternity Hospital, Dublin, Ireland; ${ }^{2}$ Radiology, National Maternity Hospital, Dublin, Ireland; ${ }^{3}$ Biostatistics - CSTAR School of Public Health and Population Science, University College Dublin, Dublin, Ireland; ${ }^{4}$ School of Medicine and Medical Sciences, University College Dublin, Dublin, Ireland

\subsection{6/archdischild-2014-307384.453}

Background Term infants with NE of hypoxic-ischaemic origin, have been exposed to generalised oxidative injury which may cause excessive cytokine production and release in serum and CSF. Cytokine levels may correlate with severity of brain injury and aid in outcome prediction.

Objective To investigate the relationship between serum and CSF biomarkers and NE in a group of term infants exposed to perinatal hypoxia-ischaemia compared to controls.

Design/Methods Levels of serum and CSF biomarkers [VEGF, IL-8, Epo, GM-CSF] were serially measured over day 1-11 in a group of term newborns with NE and controls (serum only). These values were compared to grade of encephalopathy defined by Sarnat score. Results Twelve control and 82 cases had serum samples collected (Grade $0 \mathrm{NE}=6$, Grade I NE $=23$, Grade II NE $=42$, Grade III $\mathrm{NE}=11$ ). Thirty-nine infants underwent TH, 4 infants died. Controls had significantly lower serum Epo on day 1-2 compared with cases (p-values $<0.05)$. Grade II/III NE was significantly associated with elevated serum Epo (Day 2), IL-8 (Day 2 and 6-8) (pvalues $<0.05$ ) and with decreased VEGF (Day 1). Grade II/III NE was best predicted by Epo and IL-8 (Day 2) and VEGF (Day 1) (pvalues $<0.05)$. CSF biomarker levels $(\mathrm{n}=34$ infants) were not significantly associated with abnormal NE grade.

Conclusions Term infants exposed to perinatal hypoxia-ischaemia have elevated levels of serum biomarkers compared to 
controls. Abnormal NE grade is best predicted by day 2 serum Epo and IL-8 while CSF levels were not predictive of outcome. Serum biomarkers may have a role in long term outcome prediction following NE.

\section{PS-158 EMERGENCY TRIAGE ASSESSMENT AND TREATMENT (ETAT) TRAINING IN A SEMIRURAL HOSPITAL IN SIERRA LEONE - RETENTION OF KNOWLEDGE AND FEED BACK}

${ }^{1}$ A Lewis, ${ }^{1} \mathrm{~L}$ Sendell, ${ }^{1} \mathrm{~T}$ Hildebrandt, ${ }^{2} \mathrm{M}$ Bryant. ${ }^{1}$ Paediatrics, Princess of Wales Hospital, Bridgend, UK; ${ }^{2}$ General Practice, ABMU Health Board, Swansea, UK

\subsection{6/archdischild-2014-307384.454}

Background and aims ETAT is a well established training course initiated through WHO in 2005. It is aimed at resource poor countries and teaches triage of children leading to effective emergency treatment. The course is run over 3 days consisting of tutorials and practical skill stations. We delivered ETAT for the first time in a semirural hospital situated in Lunsar, Sierra Leone.

Methods 20 candidates participated in the course. Candidates were asked to complete a test consisting of 25 points and to give structured feed back after completion of all modules.

Results 20 initial post course assessments were performed with an average score of $78.2 \%$. overall feedback was very good with all categories rated as excellent or good. Overriding themes were:

"The training should be repeated on a regular basis"

"Tutorials and practical skill stations will help me to implement this knowledge into practice".

Conclusions ETAT training is well received with all feedback categories rated as either excellent or good. The initial testing demonstrated good knowledge of topics taught with an overall score of $78.2 \%$. Post course retention of knowledge however is likely to be poor in line with previously published data. To achieve long term retention of knowledge ETAT training should be delivered repeatedly, ideally led by the local team.

\section{PS-159 BETA-AMYLOID AND S100B COULD BE VALUABLE BIOMARKERS AFTER NEONATAL HYPOXIA-REOXYGENATION. A STUDY IN NEWBORN PIGS}

${ }^{1} \mathrm{~T}$ Benterud, ${ }^{1} \mathrm{~L}$ Pankratov, ${ }^{1} \mathrm{R}$ Solberg, ${ }^{1} \mathrm{OD}$ Saugstad, ${ }^{2} \mathrm{~A}$ Skinningsrud, ${ }^{3} \mathrm{~N}$ Bolstad. ${ }^{1}$ Department of Pediatric Research, Oslo University Hospital, Oslo, Norway; ${ }^{2}$ Department of Medical Biochemistry, Akershus University Hospital, Oslo, Norway; ${ }^{3}$ Department of Medical Biochemistry, Oslo University Hospital, Oslo, Norway

\subsection{6/archdischild-2014-307384.455}

Background and aims The use of biomarkers is an important strategy for risk stratification for neonates admitted to the NICU after perinatal asphyxia. Total Tau (t-Tau), phosphorylatedTau (pTau) and Beta-Amyloid (1-42) (b-A) in CSF, are useful biomarkers in various neurological disorders, such as Alzheimer's. Few, if any, experiments have investigated the possible association between oxidative stress in the neonates and the levels of these proteins.

\section{Abstract PS-159 Table}

\begin{tabular}{|l|l|l|l|l|l|}
\hline \multicolumn{1}{|c|}{ CSF } & Severe Hypox & $P$-Value & Mod.Hypox & $P$-Value & Control \\
\hline S100B ng/ml & $40(36)$ & $<0.01$ & $39(39)$ & $<0.05$ & $12(9)$ \\
\hline$\beta-A ~ p g / m l$ & $1002(401)$ & 0.01 & $1076(206)$ & $<0.05$ & $1290(143)$ \\
\hline p-Tau pg/ml & $85(49)$ & n.s. & $95(64)$ & n.s. & $68(15)$ \\
\hline
\end{tabular}

\section{Abstract PS-159 Table 2}

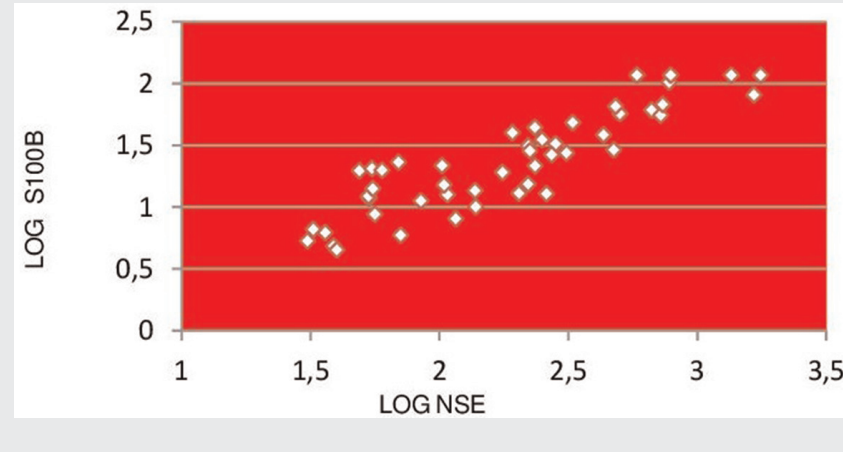

Objective To study any correlations between the levels of t-Tau, $\mathrm{p}$ Tau, b-A, S100B and NSE and oxidative stress in the newborn pig. Methods Fifty-four newborn piglets, age12-36 h, were included. One control group $(n=6)$ and 2 experimental groups $(n=24)$, exposed to global hypoxia $(8 \% \mathrm{O} 2)$ until $\mathrm{BE}$ reached $-15 \mathrm{mmol} / \mathrm{l}$ (moderate hypoxia) or $-20 \mathrm{mmol} / \mathrm{l}$ (severe hypoxia) or BP fell below $20 \mathrm{mmHg}$. The pigs were observed for $9.5 \mathrm{~h}$. CSF was collected $9.5 \mathrm{~h}$ after the intervention.

Results

Discussion To our knowledge this is the first study investigating the levels of Tau, p-Tau and b-Amyloid in a neonatal animal model after hypoxia-reoxygenation. The reduced level of CSF bAmyloid may reflect the death of neurons after neonatal hypoxia. A strategy of measuring several biomarkers should be applied when assessing the prognosisafter perinatal asphyxia.

Conclusion These findings show that b-amyloid and S100b are significantly changed in neonatal pigs subjected to hypoxia compared to controls, thus they may be valuable biomarkers after perinatal asphyxia.

\section{Long Term Follow Up}

\section{PS-160 VOLUME OF CEREBELLUM AND THALAMUS IS ASSOCIATED WITH WORKING MEMORY PERFORMANCE IN CHILDREN AND ADOLESCENTS BORN VERY PRETERM}

${ }^{1}$ F Wehrle, ${ }^{2} \mathrm{~A}$ Buchmann, ${ }^{3} \mathrm{~A}$ Hüsser, ${ }^{4} \mathrm{~B}$ Latal, ${ }^{4} \mathrm{R}$ Huber, ${ }^{5} \mathrm{R}$ O'Gorman, ${ }^{6} \mathrm{~L}$ Kaufmann, ${ }^{5} \mathrm{H}$ Speckbacher, ${ }^{3} \mathrm{C}$ Verrey, ${ }^{1} \mathrm{C}$ Hagmann. ${ }^{1}$ Division of Neonatology, University Hospital of Zurich, Zurich, Switzerland; '2Department of Neurology, University Hospital of Zurich, Zurich, Switzerland; ${ }^{3}$ Department of Psychology, University of Zurich, Zurich, Switzerland; ${ }^{4}$ Child Development Center, University Children's Hospital, Zurich, Switzerland; ${ }^{5}$ Center for MR Research, University Children's Hospital, Zurich, Switzerland; ${ }^{6}$ Department of Psychiatry and Psychotherapy A, General Hospital, Hall in Tyrol, Austria

\subsection{6/archdischild-2014-307384.456}

Background Children and adolescents born very preterm (VPT) are at increased risk for altered brain development [1] and impaired cognitive performance [2]. Decreased regional brain volume in VPT infants has been associated with later working memory deficits [3]. This study aims to identify associations between regional brain volume and working memory performance in VPT children.

Design/methods Thirty-three VPT children between 10 and 16 and 34 term-born peers were examined. Three-dimensional T1and T2-weighted MR images were acquired on a 3T GE scanner. Regional brain volumes were calculated using FreeSurfer 5.3.0. Working memory was assessed using the spatial working memory (SWM) task of the Cantab test battery. 